\title{
Unsuccessful Subjective Well-Being Assimilation Among Immigrants: The Role of Faltering Perceptions of the Host Society
}

\author{
M. Hendriks ${ }^{1}$ (D) M. J. Burger ${ }^{1,2}$
}

Published online: 6 August 2019

(C) The Author(s) 2019

\begin{abstract}
Immigrants in developed countries typically fail to assimilate in terms of their subjective well-being, meaning that their happiness and life satisfaction do not substantially increase with their length of stay or across generations, and therefore their subjective well-being remains lower than that of natives. This finding contrasts with migrants' own expectations and the predictions of straight-line assimilation theory, along with the general improvement of immigrants' objective living conditions with their length of stay. Using European Social Survey data, we show that the gradual development of less positive perceptions of the host country's economic, political, and social conditions is associated with less positive subjective well-being trajectories among first generation immigrants and across migrant generations in developed European countries. This negative association is particularly strong for immigrants whose societal conditions strongly improved by migration and immigrants who arrived after childhood. However, compared with natives, the more positive societal perceptions of first-generation immigrants are associated with a subjective well-being advantage. We attribute these findings to immigrants' growing aspirations and expectations that follow from their habituation to better conditions in their host country and fewer (more) comparisons to the inferior (better) conditions of the people in their home (host) country. Our findings suggest that delaying or decelerating the process of immigrants' faltering societal perceptions is a promising pathway to improved subjective well-being assimilation and reduced frustration about their perceived lack of progress.
\end{abstract}

Keywords Migration · Happiness · Life satisfaction · Frame of reference $\cdot$ Assimilation

Electronic supplementary material The online version of this article (https://doi.org/10.1007/s1090 2-019-00164-0) contains supplementary material, which is available to authorized users.

M. Hendriks

hendriks@ese.eur.nl

1 Erasmus Happiness Economics Research Organisation (EHERO), Erasmus University Rotterdam, Burgemeester Oudlaan 50, 3062 PA Rotterdam, The Netherlands

2 Department of Applied Economics, Erasmus University Rotterdam, Burgemeester Oudlaan 50, 3062 PA Rotterdam, The Netherlands 


\section{Introduction}

The subjective well-being of international migrants in developed countries generally does not increase as their length of stay in the host country progresses (Safi 2010; Obućina 2013; Stillman et al. 2015; Calvo and Cheung 2018; Hendriks et al. 2018). In addition, the second generation does not have higher subjective well-being than their immigrant parents (e.g., Safi 2010). These outcomes imply that many immigrants fail to assimilate to the higher subjective well-being levels of native populations in developed host countries (Hendriks 2015). ${ }^{1}$

This would seem to run counter to many migrants' expectations. Often, migrants view moving abroad as an investment into their future and that of their children. They may reasonably expect to face initial challenges, such as adjusting to a new culture, learning a new language, finding their desired job, and building a new social life, but overcoming these hardships is generally expected to lead to improvements in well-being in the long run. The non-improving level of subjective well-being also seemingly contradicts the notion of classical assimilation theory that after overcoming the frequently high socio-economic costs of migration (Sjaastad 1962), the objective well-being conditions of immigrants in developed countries tend to improve in a "straight line" over time and further progress across generations (Alba and Nee 1997). Encouragingly, the empirical literature generally confirms that the average immigrant and immigrant generation achieve objective progress in many important well-being domains, including improvements in economic mobility (Chiswick et al. 2005), educational and occupational attainment (Farley and Alba 2002; Zuccotti et al. 2017), social integration (Depalo et al. 2006), and acculturation (Manning and Roy 2010), even if progress is not experienced by all immigrant groups (Portes and Zhou 1993) and in every life domain (Rumbaut 1997). It is apparent that immigrants' objective reality differs considerably from their subjective reality - in terms of well-being assimilation-a distinction that Stillman et al. (2015) directly observe by comparing immigrants' steeply rising earnings to their declining subjective well-being.

The lack of subjective well-being assimilation is undesirable, not only for the immigrants themselves but also for their hosting countries. For immigrants, perceptions of experiencing inferior conditions compared with the native population, along with limited progress in realizing their aspirations, can be a source of dissatisfaction and frustration. Less satisfied immigrants may acculturate less (Richardson 1967), exhibit negative attitudes and behaviours towards society (Johnson and Fredrickson 2005), and contribute less to society (De Neve et al. 2013). In a rapidly globalizing world with an ever expanding immigrant population, and in light of these likely negative consequences of limited subjective wellbeing assimilation, it is important to understand why immigrants do not perceive their lives to be improving over time.

\footnotetext{
1 Broadly defined, assimilation refers to "the decline, and at its endpoint the disappearance, of an ethnic/racial distinction and the cultural and social differences that express it" (Alba and Nee 1997, p. 863). Subjective well-being refers to the subjective enjoyment of one's life (Veenhoven 2012), which covers the extent to which an individual experiences both affectively pleasant feelings (i.e., an affective component) and perceives oneself as obtaining what one wants from life (i.e., a cognitive component). Commonly used subjective well-being measures are global self-report measures of happiness or life satisfaction. Although life satisfaction taps more (less) into the cognitive (affective) component, it is closely related to happiness, both conceptually and empirically. Accordingly, the theoretical and empirical insights of this study hold for happiness, life satisfaction, and subjective well-being.
} 
Assimilation has a positional and a progress component. The focus of the literature on migrant well-being has been on the positional component of assimilation. This literature offers various explanations for the lower subjective well-being levels of immigrants compared to the native populations in developed countries, including their perceived discrimination (Safi 2010), less prosperous living conditions, stronger feelings of social isolation (De Vroome and Hooghe 2014), and cultural heritage (Senik 2014). However, the current literature has bypassed the question why immigrants tend to experience a stagnant level of subjective well-being (i.e., the progress component).

Piore (1979) discussed one possible reason for the lack of progress in subjective wellbeing in his work on labour migrants in the US in the mid-twentieth century. Piore posited that the initially positive evaluations of one's migration experience disappeared or at least diminished over time and across generations as migrants began to evaluate their conditions in the host country through an increasingly critical lens because of increasing aspirations and expectations, and therefore gradually developed less positive perceptions of their life circumstances in the host country. However, Piore's (1979) thesis that declining perceptions of the host society impair subjective well-being assimilation has remained untested.

This paper aims to contribute to filling this void in the literature on migrant well-being by theorizing and exploring the extent to which-and under what conditions-faltering perceptions of the host country's societal conditions are associated with the subjective well-being assimilation of immigrants in developed European countries over time and across generations. The societal conditions considered here are the country's economic, political, and social macro-environment. While the development of host country perceptions and well-being over time and across generations is of primary interest (i.e., the progress component), we additionally investigate how differences in societal perceptions between natives and immigrants affect the immigrant-native gap in subjective well-being (i.e., the positional component).

The remainder of this paper is organised as follows. In Sect. 2, we discuss why migrants' perceptions of their host country's conditions may falter and in turn, why this may impair their subjective well-being assimilation. Section 3 outlines the data and empirical strategy, and the empirical results are presented in Sect. 4. Section 5 concludes the paper with a brief discussion of our findings.

\section{Theoretical Background}

\subsection{Changing Societal Perceptions and Their Influence on Subjective Well-Being}

According to adaptation theories of well-being (Michalos 1985; Diener et al. 2006; Luhmann et al. 2012), subjective interpretations of reality can differ considerably from objective reality and these perceptions are important and unique determinants of subjective wellbeing (Jahedi and Méndez 2014). For instance, the objective quality of the environment can diverge from perceptions of that environment (Okulicz-Kozaryn 2013) and perceptions of economic mobility do not necessarily reflect actual economic mobility (Graham and Pettinato 2001). Perhaps the most pre-eminent example illustrating the importance of this "relative" dimension of subjective well-being concerns individual income. Once an individual's financial needs are met, their happiness depends much more on the relative perception of their income in relation to past income and to the perceived incomes of their peers than on 
their absolute income level (Easterlin 2001; Clark et al. 2008). Immigrants seem to be no exception in this regard (Vohra and Adair 2000; Gokdemir and Dumludag 2012).

These insights suggest that immigrants' perceptions of their conditions could play a role in determining their subjective well-being assimilation if these perceptions change over time. In line with Piore's (1979) thesis, the literature documents that immigrants initially have extraordinarily positive perceptions of more developed hosting societies. For instance, their perceived educational opportunities, trust in public institutions, and satisfaction with the government in more developed hosting countries tend to markedly exceed those of the native populations (Suarez-Orozco 1987; Michelson 2003; Röder and Mühlau 2012; Maxwell 2010). However, these studies also show that immigrants' trust in public institutions and government satisfaction declines with their length of stay, suggesting that their initial enthusiasm about the societal conditions in the host country fades over time. Based on the above considerations we formulate the following hypothesis:

Hypothesis 1 Declining perceptions of the host society, as measured by an index of migrants' economic satisfaction, government satisfaction, trust in public institutions, and social trust, negatively mediate the relationship between immigrants' length of stay and subjective well-being.

\subsection{Channels and Conditions}

Piore (1979) posited that immigrants' declining perceptions of host societies may occur due to the higher aspirations and expectations immigrants gradually develop as they grow accustomed to the better conditions in their host country and compare those conditions less often with the typically inferior conditions in their home country. Consequently, according to Piore (1979; p. 171), "the disjuncture between aspirations and opportunities is likely to occur $[\ldots]$ in settled migration communities and in the second generation".

Adaptation theories of well-being and the migration literature generally provide supporting evidence for the mechanism proposed by Piore (1979), as detailed below. The starting point of this mechanism is a change over time in immigrants' orientations. The related literatures on acculturation (Berry et al. 2006), assimilation (Alba and Nee 1997) and transnationalism (Vertovec 2009) observe that most migrants gradually develop economic and socio-cultural ties in the host country while possibly maintaining their cultural heritage and social networks from their home country. Traditional labour migration theories also generally recognize that although immigrants initially compare themselves only to people in their home country, many labour migrants ultimately settle permanently and then start orienting themselves more towards the host society as their ties with the home society weaken (Stark and Taylor 1991).

One implication of these shifting orientations is that many immigrants engage increasingly less in activities that stimulate comparisons to people in the home country (see, e.g., Stark and Taylor 1991 on "reference group substitution"). They may for instance visit and communicate less with friends and family in their home country, or stop following the news about the home country. Additionally, as people mostly compare their current conditions to those of the recent past (Helson 1964), immigrants who reside in the host country for longer periods compare the host society's current societal conditions more to past conditions that they experienced in the host country as opposed to the home country. Qualitative and quantitative studies mostly support the idea that the frames of reference shift partially from home countries to host countries over time, resulting in a dual frame of 
reference (Reese 2001; Menjívar and Bejarano 2004; Gelatt 2013; Franzini and FernandezEsquer 2006; Akay et al. 2017).

This shifting frame of reference may affect migrants' aspirations. Generally, higher reference points, as reflected by upward comparisons to better-off people or more desirable situations, lead to higher aspirations (Clark et al. 2008; Festinger 1954). In turn, adaptation theories of well-being posit that the way people experience and evaluate their lives is strongly based on the gap between what one wants (aspirations) or expects (expectations) and what one has (objective living conditions). Accordingly, upward comparisons followed by higher aspirations tend to reduce satisfaction with one's situation and subjective wellbeing [see, for instance, the tunnel-effect described by Hirschman and Rothschild (1973); for suggestive evidence on migrants, see Vohra and Adair (2000), Gokdemir and Dumludag (2012), Akay et al. (2017)].

A likely contingent factor in the impact of these shifting reference points on one's perceptions of the host society is the development gap between the host and the home country. Shifting reference points can be expected to affect aspirations and perceptions more when there is a wider gap between the level of the old reference points (situated in the home country) and the new reference points (increasingly situated in the host country). This gap in reference points is larger for migrants whose societal conditions objectively improve more by migrating (i.e., the home country provides migrants from less developed countries with lower reference points). Downward comparisons to the home country provide migrants from less developed countries, at least initially, with lower aspirations and these migrants therefore evaluate the societal conditions in the host country more positively than migrants from more developed countries (Röder and Mühlau 2012). However, this relative "advantage" of migrants from less developed countries can be expected to decline with the length of stay because of decreasing comparisons with the inferior conditions in their home country, resulting in relatively more quickly rising aspirations (Czaika and Vothknecht 2014; Böhme 2015) followed by more quickly declining perceptions of the host society and, in turn, less subjective well-being assimilation. ${ }^{2}$ Therefore,

Hypothesis 2a The mediating role of immigrants' declining perceptions of the host society in their subjective well-being assimilation is moderated by the development gap between the home and host countries.

The process outlined above also suggests that perceptions may falter less for migrants whose reference points shift less. A notable group in this respect are migrants who arrived in the host country at a young age. They tend to have fewer memories of and connections with the home country than migrants who arrived as adults. Therefore, migrants who arrived at a young age, particularly those who arrived before adolescence (the so-called 1.5 and 1.75 generations; Rumbaut 2004), may compare their situation less often to the situation in their home country regardless of their length of stay, implying that their reference points shift less. Therefore,

\footnotetext{
2 Alternative processes that may affect perceptions of host country conditions include changes in preferences (e.g., political and cultural preferences) and values. Although declining objective societal conditions may cause declining societal perceptions, it cannot provide a full explanation for declining societal perceptions because migrants' declining perceptions are also found in static research designs that compare perceptions of recent and established migrants at the same point in time (e.g., Safi 2010; Stillman et al. 2015).
} 
Hypothesis $\mathbf{2 b}$ The mediating role of immigrants' declining perceptions of the host society in their subjective well-being assimilation is moderated by age at migration (during vs. after childhood).

Adaptation theories of well-being suggest that the process of shifting reference points and aspirations is a mostly automatic and universal process that occurs at a similar pace and to a similar extent for all socio-demographic groups (Diener et al. 2006; Luhmann et al. 2012). These features of the adaptation process suggest that the process of faltering societal perceptions is widespread among migrants whose reference points significantly shift and whose reference points differ considerably between the host and home countries. Therefore,

Hypothesis 2c The mediating role of immigrants' declining perceptions of the host society in their subjective well-being assimilation holds regardless of their socio-economic characteristics (the migrant's gender, education level, income, and domicile). ${ }^{3}$

\subsection{The Second Generation and Natives}

Most second-generation immigrants rarely compare their country of residence to the home country of their parents, meaning that their frame of reference tends to be closer to that of the native population (a single "country of residence" frame of reference) than the dual frame of reference of first-generation immigrants (Maxwell 2010). By implication, secondgeneration immigrants and the native population can be expected to have higher reference points and aspirations - and thus less positive perceptions of similar living conditionsthan the majority of first-generation immigrants who originate from less developed countries. In other words, second-generation immigrants and natives can be expected to take the typically good societal conditions in developed host countries for granted more than most first-generation immigrants. Indeed, the positive perceptions of society seem to continue faltering across generations, as the second generation generally has lower levels of social trust (Dinesen and Hooghe 2010) and government satisfaction (Maxwell 2010) than firstgeneration immigrants do. Therefore,

Hypothesis 3 The more positive societal perceptions of first-generation immigrants are associated with a subjective well-being advantage over second-generation immigrants.

Hypothesis 4 The more positive societal perceptions of first-generation migrants are associated with a subjective well-being advantage over natives.

\footnotetext{
${ }^{3}$ In the absence of data on migrants' aspirations and reference points (Gelatt 2013), testing the underlying channels is beyond this article's scope. We acknowledge the possible existence of other moderators that are not considered in this study due to data limitations, such as the migrant's degree of acculturation, the difference between circular and non-circular migrants, and the reasons for migration.
} 


\section{Data and Methodology}

In the absence of long-running panel databases that track immigrants' perceptions, the broad assimilation literature commonly resorts to cross-sectional data or panel data that cover only a few years (e.g., Chiswick et al. 2005). Given our interest in assimilation over the life course, cross-sectional, multi-country data taken from the 2010-2016 period (rounds 5-8) of the bi-annual European Social Survey (ESS) are used. The analysis sample includes respondents residing in 17 developed European countries, including the EU15 (minus Luxembourg) and three EFTA countries (Iceland, Norway, and Switzerland).

The analysis is divided into four parts. In the first part, we test Hypothesis 1 by exploring how the changing societal perceptions of first-generation migrants relate to their subjective well-being development. The second part tests Hypothesis 2 by exploring the extent to which the mediating role of changing societal perceptions is conditional on various migrant characteristics. The third part tests Hypotheses 3 and 4 by exploring how societal perceptions relate to the subjective well-being assimilation of second-generation immigrants and the subjective well-being gap between immigrants and natives. The fourth part includes various robustness checks.

\subsection{Outcome Variable}

The ESS includes two self-report measures of subjective well-being: life satisfaction and global happiness. The main analysis employs the more commonly used life satisfaction variable, which is formulated as "All things considered, how satisfied are you with your life as a whole nowadays?". The numerical response scale ranges from 0 (extremely dissatisfied) to 10 (extremely satisfied). The global happiness variable is used to conduct a robustness check.

\subsection{Explanatory Variables}

First-generation immigrants are defined as individuals who were born abroad to foreignborn parents, and second-generation immigrants are defined as individuals who were born in the country of residence to foreign-born parents. All first and second-generation immigrants who responded to the survey are included, regardless of their country of origin. Natives are defined as individuals who were born and whose parents were born in the country of residence. Foreign-born children with native parents and individuals with mixed parental backgrounds (the 2.5 generation) are excluded from the sample due to their ambiguous immigrant status. In ESS rounds 5-8, participants indicate the exact year of their migration. Years since migration is calculated by subtracting the exact year of migration from the year of survey completion. We use this continuous length-of-stay variable for the first two parts of our analysis. In ESS rounds 1-4, immigrants are given five possible answers to indicate how long ago they migrated to their country of residence: (a) within the last year, (b) 1-5 years ago, (c) 6-10 years ago, (d) 11-20 years ago, or (e) more than 20 years ago. A robustness check is performed in which we reclassified the answers from rounds 5-8 into the five length-of-stay categories used in ESS rounds 1-4 to utilize all survey rounds. 


\subsection{Mediator Variable}

The mediator variable is a self-constructed index of the immigrant's reported perceptions of the host country's societal conditions that includes four indicators and spans three dimensions. Economic satisfaction captures the immigrant's perceptions of the economic environment of the host country; government satisfaction and trust in public institutions capture his or her perceptions of the institutional environment of the host country; and social trust captures his or her perceptions of the social environment of the host country. The exact measures of these indicators are presented in Table 1. We integrated these four indicators into an index based on equally weighted scores because we expect a downward trend for each component and because their high statistical correlation raises multicollinearity issues when considered separately (Cronbach's a $=0.76$ ). In an auxiliary analysis, we explore the mediating roles of the separate components. ${ }^{4}$

\subsection{Control Variables}

To mitigate the confounding role of spatial distribution on the perceptions and life satisfaction of the respondents, we control for respondents' domicile, region of residence, ${ }^{5}$ and country of residence. A second set of control variables aims to address the possibility that migration flows vary with the length of stay and bias the associations between our variables of interest. Therefore, we include country-of-origin dummies and migration flow dummies (interacting country-of-residence dummies and region-of-origin dummies) ${ }^{6}$; the latter capture the possibility that migrants who arrived more recently engage in more "happinessefficient" migration streams. ${ }^{7}$ We also control for whether the immigrant comes from a former colony of the host country because a colonial tie may affect immigrants' perceptions of the host country. A third set of control variables addresses potential biases due to the pooling of multiple survey rounds. We include year dummies to capture time-related shocks that are common to all host countries and country-specific (linear) time trends that capture differences in time trends between countries. The fourth and final set of control variables includes socio-demographic controls that are usually included in subjective

\footnotetext{
${ }^{4}$ We focus in this paper on immigrants' societal perceptions rather than their perceptions of their personal conditions for three reasons. First, the immediate societal "shock" experienced by all immigrants upon arrival in the host country reveals the exact pattern of changing perceptions of the host country from the moment of arrival, whereas progress in personal conditions frequently appears only in the long run. Second, the objective difference between the host and home countries' societal conditions can be derived for every immigrant, while this difference is more ambiguous for personal conditions due to the missing information regarding the immigrant's pre-migration personal conditions. Third, evaluations of societal conditions are available in all survey rounds, while evaluations of personal conditions (job satisfaction and satisfaction with one's living standard) are available only in specific rounds. Moreover, the ESS and other relevant datasets include limited information about the respondents' objective financial and job characteristics, which would constrain us in distinguishing whether changing perceptions follow from changing objective finan$\mathrm{cial} / \mathrm{job}$ characteristics or changing evaluation criteria.

${ }^{5}$ NUTS 2 data are used for countries in which this information is consistently available across survey rounds. These countries are Austria, Switzerland, Denmark, Spain, the Netherlands, Norway, Portugal, and Sweden. NUTS 1 data are used for the other countries.

6 The migration flow dummies are based on region-of-origin dummies (see Online Appendix B for the considered origin regions) instead of country-of-origin dummies because the excessive number of possible combinations when interacting the origin and destination countries will lead to model estimation problems.

7 For instance, immigrants who migrated after their home country became part of the European Schengen area have more (and thus potentially better-fitting) host countries to select from than earlier migrants did.
} 


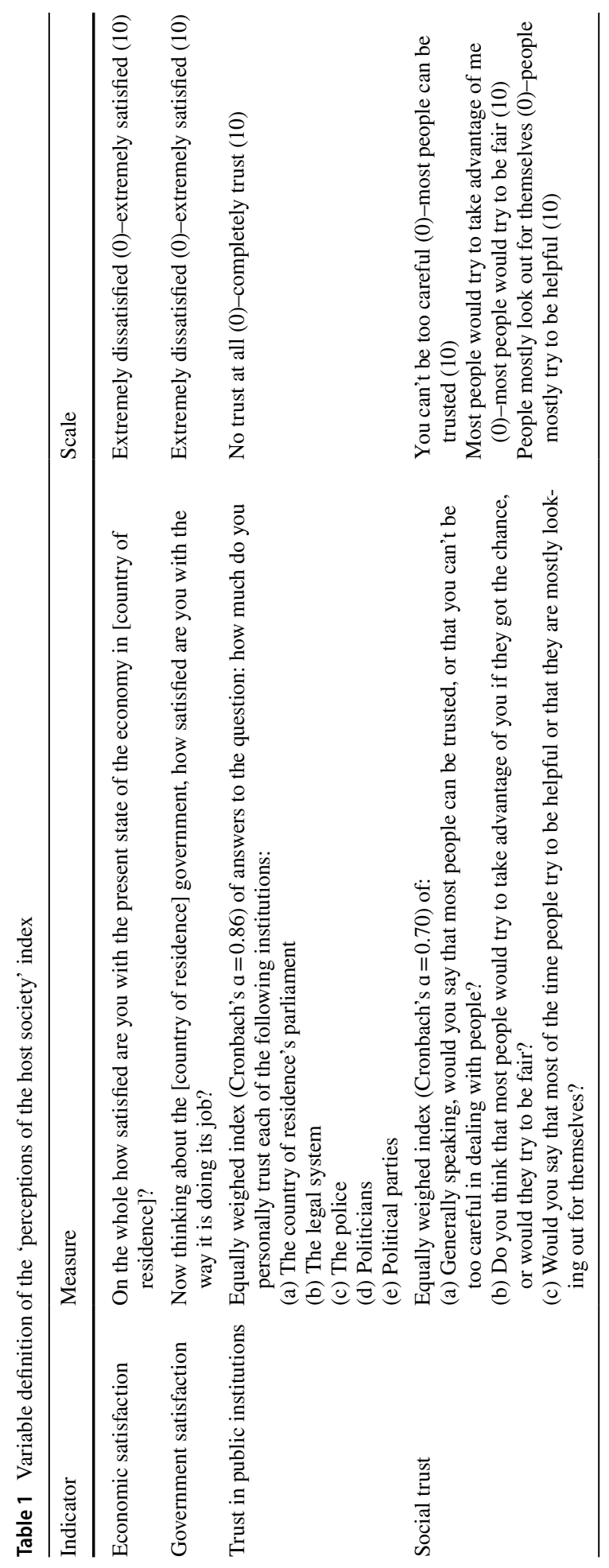


well-being regressions: age, age squared, gender, having a partner and/or children, perceived health, employment status, household income (ln), and years of education $(\ln ) .^{8}$ The measures and summary statistics of all individual-level control variables and the sample composition are presented in Online Appendices A and B.

\subsection{Moderator Variables}

The development gap between the home and host countries is calculated using the difference in the home and host countries' scores on the human development index (HDI) in the year of the interview. The HDI, ranging from zero to one, comprises three domainshealth, education, and standard of living - that together provide a good overview of a country's societal environment. For age at migration, we follow Rumbaut's (2004) approach by distinguishing migrants who arrived during childhood (before 13 years old) from those who arrived as adolescents or adults (13 years or older). The socio-demographic moderator variables are based on the variables described in Sect. 3.4.

\subsection{Empirical Methodology}

Our baseline model shows the relationship between the immigrant's length of stay and subjective well-being by estimating an ordinary least squares (OLS) model with robust standard errors clustered at the country-year level. ${ }^{9}$ This model has the following specification:

$$
S W B_{i j o t}=\beta_{1} Y S M_{i j o t}+\Theta X_{i j o t}+\varepsilon_{j}+\tau_{t}+\varepsilon_{j} \tau_{t}+\lambda_{o}+\lambda_{o} \varepsilon_{j}+\mu_{i j o t}
$$

In this model, $\mathrm{SWB}_{\mathrm{ijot}}$ denotes the overall life satisfaction of immigrant $\mathrm{i}$ in country $\mathrm{j}$ from origin o in year t. $\mathrm{YSM}_{\mathrm{ijot}}$ represents years since migration. Vector $X_{i j o t}$ includes the individual-level controls; vector $\varepsilon_{j}$ includes the country-of-residence dummies; vector $\tau_{t}$ contains the year dummies; vector $\varepsilon_{j} \tau_{t}$ includes the country-specific time trends; vector $\lambda_{o}$ includes the country-of-origin dummies; and vector $\lambda_{o} \varepsilon_{j}$ includes the migration flow dummies. Finally, $\mu_{i j o t}$ is a residual error.

To examine the role of perceived societal conditions in subjective well-being assimilation, we assess whether the relationship between length of stay and subjective well-being changes when also controlling for the immigrant's societal perceptions. This second model has the following specification:

$$
S W B_{i j o t}=\beta_{1} Y S M_{i j o t}+\boldsymbol{\Omega P H} \boldsymbol{S}_{i j o t}+\Theta X_{i j o t}+\varepsilon_{j}+\tau_{t}+\varepsilon_{j} \tau_{t}+\lambda_{o}+\lambda_{o} \varepsilon_{j}+\mu_{i j o t}
$$

Compared with Eq. 1, this model additionally includes the predictor variable PHS $_{i j o t}$, which constitutes the index of perceptions of the host society. A comparison of the first model and the second model will show the association between immigrants' societal perceptions and their subjective well-being development over time. The OLS models are complemented by mediation tests that examine the extent to which perceptions of the host society mediate the relationship between the immigrant's length of stay and subjective well-being. Given our multilevel data, we estimate this mediating role using the

\footnotetext{
8 Senik (2014) argues that the ESS education measures suffer from substantial measurement error when it comes to immigrants. We verified that the exclusion of education level has no noteworthy effect on our results.

9 We implicitly presume cardinality for our life satisfaction variable, which is a common assumption in happiness economics because linear and ordinal estimation techniques produce similar results in most cases, while linear models are easier to interpret (Ferrer-i-Carbonell and Frijters 2004).
} 
"ml_mediation" command in Stata with bias-corrected bootstrapped standard errors clustered at the country-year level (Ender 2012).

In part 2, interaction terms between years since migration and migrant characteristics will be added to these baseline specifications to explore whether the hypothesized mediating role of societal perceptions is moderated by these migrant characteristics. We estimated the conditional indirect relationships using the moderated mediation procedure proposed by Hayes (2013; Model 2) and with bias-corrected standard errors clustered at the country-year level. ${ }^{10}$ In part 3, migrant status dummies distinguishing natives, first-generation immigrants, and second-generation immigrants will replace the YSM-variable.

Given that our dataset contains only 18 units at the highest clustering level (host countries), clustering our standard errors at the country level will lead to downward biased standard errors (Cameron et al. 2008). We partly avoid this issue by clustering at the country-year level, although we acknowledge that this approach may still produce slightly downward biased standard errors. Therefore, our statistical inference ( $p$ values) in the OLS regressions is based on the wild cluster bootstrap method (Cameron et al. 2008). The wild bootstrap clustered $p$ values are computed with 1000 bootstrap iterations.

Another limitation of our estimations is that we could not account for all potential endogeneity issues. One solution to this problem would be to instrument our perceptions variable, but finding credible instruments is difficult. Instead, we recognize this problem and caution that our results should be interpreted as conditional associations rather than reflecting causal relationships.

\section{Results}

\subsection{Descriptive Statistics}

Figure 1 depicts how the life satisfaction and host country perceptions of first-generation immigrants vary with their length of stay, net of controls that are exogenous to the migration experience. As expected, no positive life satisfaction trend is observed, while firstgeneration immigrants gradually develop less favourable perceptions of the host country's societal environment.

\subsection{Main Results}

\subsubsection{First-Generation Immigrants}

We continue this first part of our analysis by exploring the extent to which these faltering perceptions of the host society are associated with immigrants' subjective well-being development. Columns 1-2 of Table 2 follow Eq. 1 and provide an alternative presentation of the results presented in Fig. 1. The results of Columns 1-2 show that there is no positive linear or curvilinear relationship between migrants' life satisfaction and length of stay, net of all exogenous controls. Following Eq. 2, the index of immigrants' perceptions of the host society is added as a predictor variable in Columns 3-4 of Table 2 . The positive

\footnotetext{
10 See https://stats.idre.ucla.edu/stata/faq/how-can-i-do-moderated-mediation-with-a-categorical-moder ator-in-stata/ for a more detailed explanation of our calculation procedure. Suest was used instead of sureg to account for the multilevel structure of our data.
} 


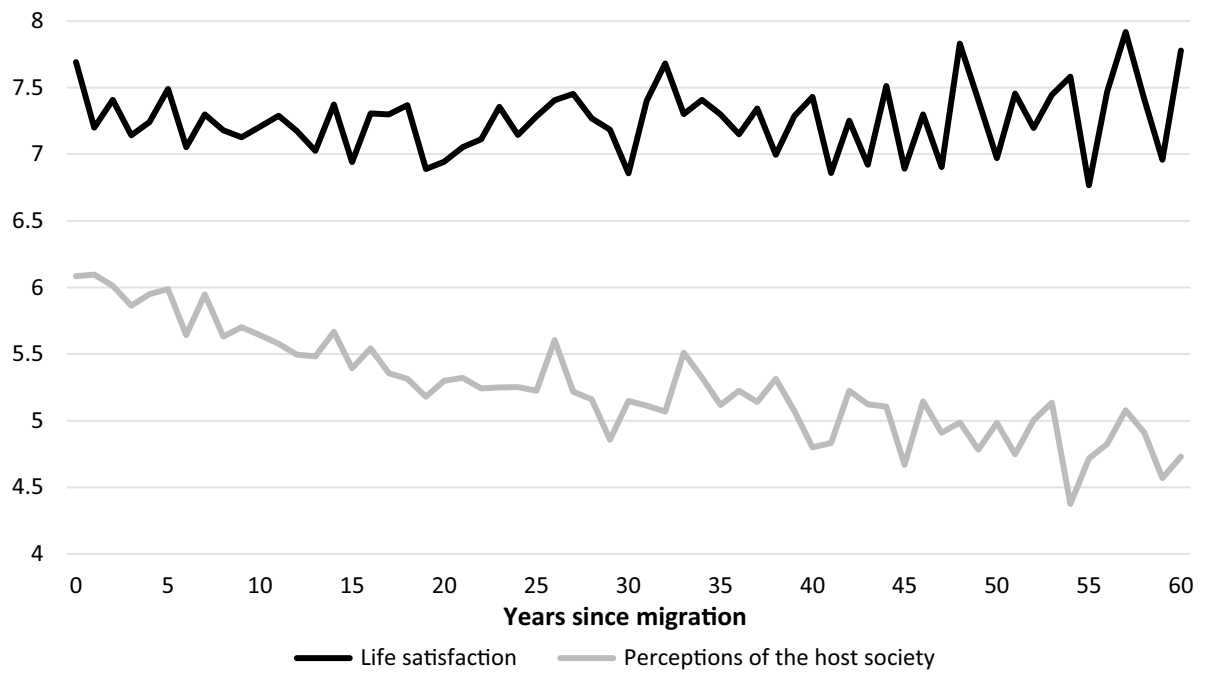

Fig. 1 Life satisfaction and perceptions of the host society by length of stay. Note: $\mathrm{N}=7044$. Means are adjusted for the following control variables: age, age $^{2}$, gender, year dummies, country of residence, countryspecific time trends, colonial ties, country of origin, and migration flow dummies. In this figure, but not in our subsequent analyses, years since migration is truncated at 60 years by adding migrants who arrived more than 60 years ago to the group of immigrants who arrived 60 years ago because there are too few respondents who arrived more than 60 years ago to give reliable averages

coefficient of this index indicates that favourable perceptions of the host society are positively associated with life satisfaction. When controlling for these societal perceptions, length of stay has a linear positive association with life satisfaction. This finding suggests that immigrants' faltering enthusiasm about the host country is associated with less positive subjective well-being trajectories. A mediation test confirms that the declining perceptions of the host society significantly and negatively mediate the relationship between length of stay and life satisfaction $(m=-0.12, S E=0.01 ; p<0.01)$.

To alleviate the concern that our results are driven by omitted variable bias, Columns 5-8 present the results when using the full set of control variables. Our observation that the length of stay and life satisfaction have a non-positive relationship is robust to the inclusion of the additional controls (see Columns 5-6). A positive curvilinear association emerges when controlling for immigrants' declining societal perceptions (see Columns 7-8). ${ }^{11}$ A mediation test confirms that immigrants' declining societal perceptions significantly suppress their life

\footnotetext{
11 The curvilinear association observed in Column 8 suggests that when accounting for the migrant's host country perceptions and a broad set of socio-demographic characteristics, migrants' life satisfaction increases after migration, peaks in the fifth year after migration (turning point $=4.5$ years), and afterwards declines. In contrast, the models excluding potentially endogenous socio-demographic characteristics (Columns 3-4) showed evidence for a positive linear but not a curvilinear relationship, suggesting that life satisfaction continues to increase with the length of stay. One likely reason for the curvilinear relationship in Column 8 is that the model controls to some extent for improvements in objective circumstances such as increasing likelihoods of a higher income, being employed, and having a partner. Consistent with this explanation, a positive linear instead of curvilinear association is observed when excluding income, employment status, health, and having a partner from Column 8. Another possible reason is that factors other than immigrants' faltering perceptions of the institutional, economic, and social environment may hinder subjective well-being assimilation, including hedonic adaptation in other dimensions (e.g., one's personal income) and a changing happiness function over time due to, for instance, changing preferences.
} 


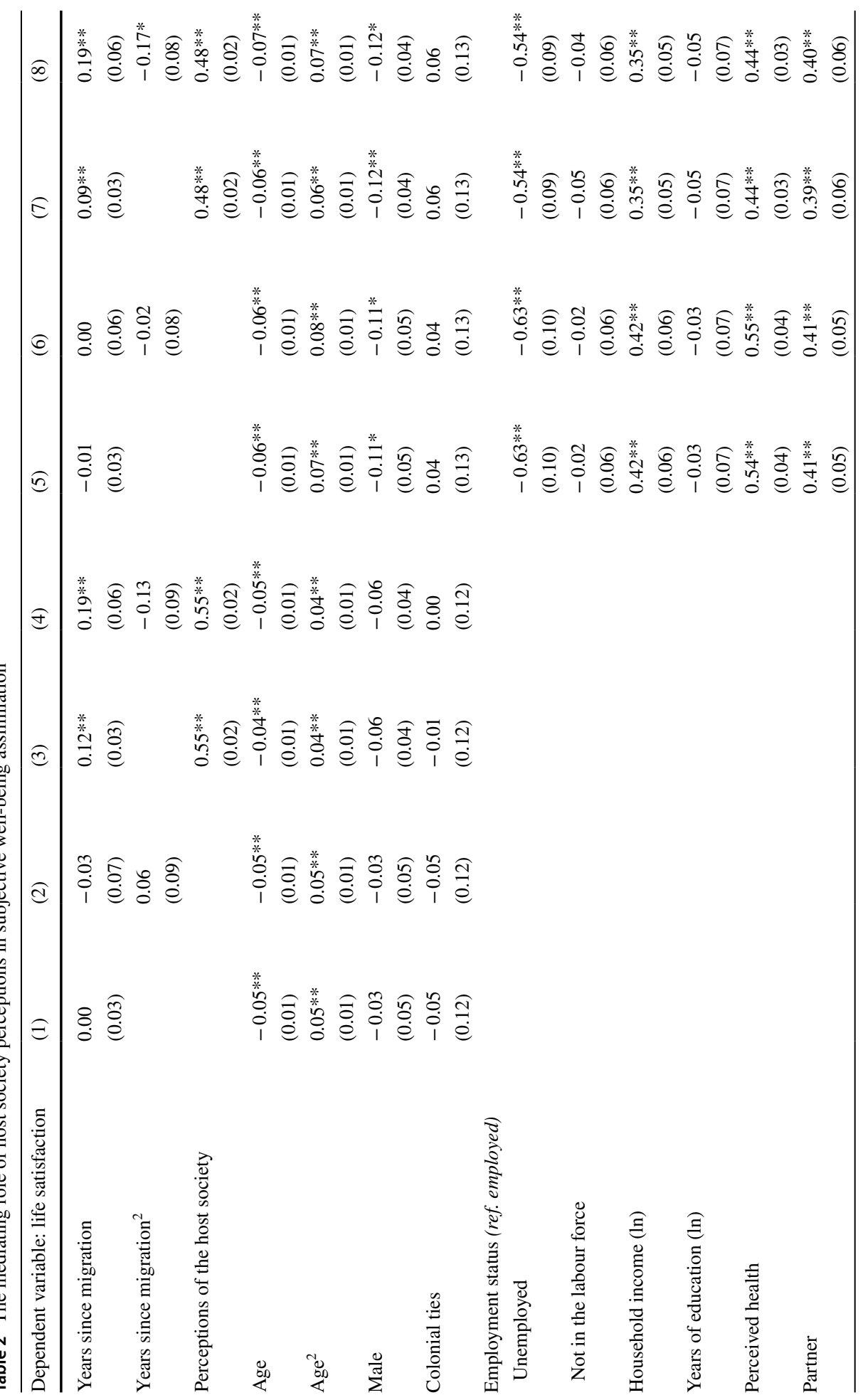




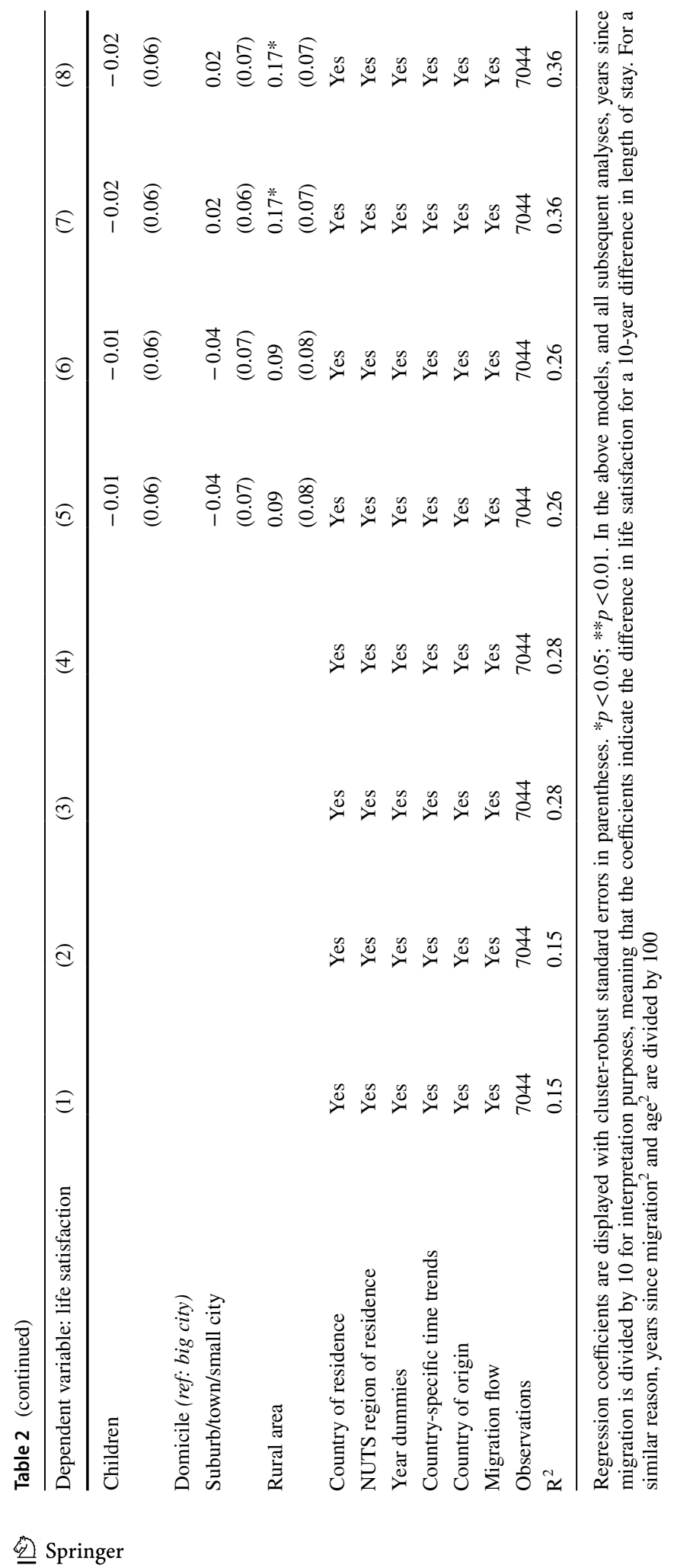


satisfaction development $(m=-0.10, S E=0.01 ; p<0.01)$, albeit to a somewhat lesser extent compared with the model that includes only controls that are exogenous to migration.

\subsubsection{Conditional Factors}

In this second part of the analysis, we examine whether the mediating role of host country perceptions is conditional on various migrant characteristics. The conditional indirect relationships are presented in Fig. 2. The negative role of the declining perceptions of

\section{Conditional indirect relationships}

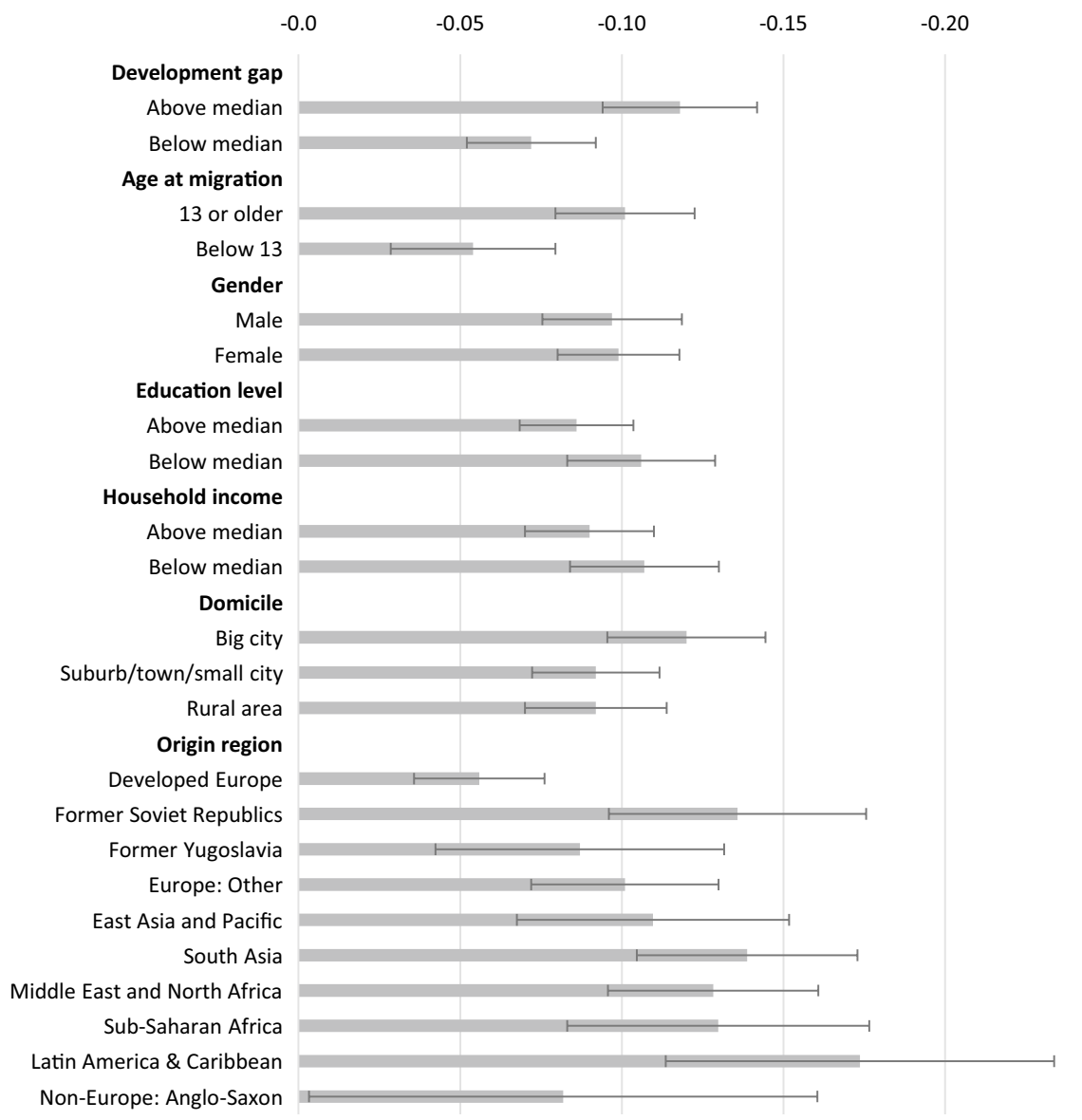

Fig. 2 Conditional indirect relationships. Note: $\mathrm{N}=7044.95 \%$ confidence intervals are presented. The control variables are as in Columns 5-8 of Table 2, except for the exclusion of country of origin, migration flow, and colonial ties in the analyses exploring the conditional role of the development gap because these variables strongly overlap with the development gap. The mean HDI level of the origin region was imputed for some small islands or microstates with unknown HDI levels. The average host-home country difference in the HDI-score for immigrants with a below-median and above-median development gap is 0.04 and 0.23 , respectively. Similar results are observed when excluding variables that are not exogenous to migration as in Columns 1-4 of Table 2 (see Online Appendix C) 
the host society holds for all considered subgroups, including migrants moving between relatively similarly developed countries and migrants moving at a young age. However, the indirect role of faltering perceptions is significantly smaller for migrants moving between more similarly developed countries $(p=0.02)$. The conditional indirect relationships by origin region are included in Fig. 2 to illustrate that the mediating role of faltering societal perceptions is consistently stronger for migrants from less developed world regions (South Asia, sub-Saharan Africa, Middle East and North Africa, East Asia and the Pacific, and Latin America and the Caribbean) than for migrants from relatively developed world regions (particularly developed Europe and the non-European Anglo-Saxon countries). In addition, we observe a marginally significant weaker mediating role of faltering host country perceptions for migrants arriving in the host country as children vis-à-vis migrants arriving as adolescents or adults $(p=0.07)$. No significant differences are observed between other migrant subgroups. These findings are broadly in line with Hypothesis 2.

\subsubsection{The Second Generation and the Migrant-Native Gap}

When controlling for non-migrant-specific exogenous controls (age, gender, country of residence and year dummies), natives and the second generation have less positive perceptions of the host society than first-generation migrants $\left(M_{\text {gen } 1}=5.40,95 \% C I[5.37,5.43]\right.$; $\left.M_{\text {gen } 2}=4.88,95 \% C I[4.81,4.94] ; M_{\text {natives }}=5.00,95 \% C I[4.99,5.01]\right)$, while natives are more satisfied with life than both migrant generations $\left(M_{\text {gen } 1}=7.20,95 \% C I[7.16,5.25]\right.$; $\left.M_{\text {gen } 2}=7.13,95 \% C I[7.04,7.21] ; M_{\text {natives }}=7.42,95 \% C I[7.41,7.43]\right)$. Table 3 includes our full set of control variables and shows that the less positive societal perceptions of second-generation migrants are associated with a life satisfaction disadvantage of 0.18 on a 0-10 scale compared with first-generation migrants, meaning that faltering perceptions of host country conditions are associated with lower subjective well-being assimilation

Table 3 The role of host society perceptions in the subjective well-being gap between immigrants, the second generation, and natives

\begin{tabular}{|c|c|c|c|c|c|c|}
\hline \multirow[b]{2}{*}{ Dependent variable: life satisfaction } & \multicolumn{4}{|c|}{ OLS regressions } & \multicolumn{2}{|c|}{ Indirect relationships } \\
\hline & (1) & (2) & (3) & (4) & $(1)-(2)$ & $(3)-(4)$ \\
\hline \multicolumn{7}{|l|}{ Migrant status (ref. Generation 1) } \\
\hline Generation 2 & $\begin{array}{l}-0.10 \\
(0.05)\end{array}$ & $\begin{array}{l}0.08 \\
(0.05)\end{array}$ & & & $\begin{array}{l}-0.18^{* * *} \\
(0.02)\end{array}$ & \\
\hline Natives & & & $\begin{array}{l}0.05 \\
(0.03)\end{array}$ & $\begin{array}{l}0.23 * * \\
(0.03)\end{array}$ & & $\begin{array}{l}-0.18^{* *} \\
(0.02)\end{array}$ \\
\hline Perceptions of the host society & & $\begin{array}{l}0.46^{* *} \\
(0.02)\end{array}$ & & $\begin{array}{l}0.36 * * \\
(0.01)\end{array}$ & & \\
\hline Observations & 8876 & 8876 & 78,792 & 78,792 & & \\
\hline $\mathrm{R}^{2}$ & 0.25 & 0.34 & 0.26 & 0.32 & & \\
\hline
\end{tabular}

Regression coefficients and indirect relationships are displayed with cluster-robust standard errors in parentheses. ${ }^{*} p<0.05 ;{ }^{* *} p<0.01$. The control variables are as in Columns 5-8 of Table 2, except for the exclusion of immigrant-specific controls (country of origin, colony, and migration flow) in Columns 3-4. Similar results are observed when excluding variables that are not exogenous to migration as in Columns $1-4$ of Table 2 (see Online Appendix D) 
across generations. Likewise, the more positive perceptions of first-generation migrants are associated with a life satisfaction advantage of 0.18 compared with natives. This finding implies that the immigrant-native gap widens considerably when controlling for the more positive societal perceptions of first-generation immigrants. These findings are in line with Hypotheses 3 and 4.

\subsection{Robustness Checks}

We first investigated the sensitivity of our results to sample selection by re-estimating our results including immigrants from all eight survey rounds using the categorical length-of-stay variable. The results of this alternative model specification are reported in Online Appendix E and confirm that faltering societal perceptions are associated with lower subjective well-being assimilation during at least the first 20 years after migration. The patterns of the conditional indirect relationships are also in line with those of our main results. As shown in Online Appendix E, the mediating role of faltering societal perceptions holds for immigrants interviewed before the financial crisis (2002-2006), during the financial crisis (2008-2012), and during the European refugee crisis (2014-2016).

Next, we conducted various robustness checks to test the robustness of our results to various validity threats. One concern in this regard is that both life satisfaction and perceptions of the host society are subjective in nature. The measurement errors of these variables may be correlated, as certain individuals may have a general tendency towards more positive or negative perceptions and/or response patterns for subjective measures. Following Graham and Nikolova (2015) and Arampatzi et al. (2018), we control for this potential bias to the greatest extent possible by including mood and optimism controls, which are jointly available in ESS rounds 3, 5 and 6. These variables capture a substantial amount of this potential endogeneity bias because being in a good mood or being an optimistic person are principal determinants of the tendency to answer subjective questions more positively. The inclusion of mood and optimism controls has a limited effect on the observed mediating role of societal perceptions (see Online Appendix F), meaning that our main results hold: more positive perceptions of the host society are associated with a life satisfaction advantage for recently arrived immigrants vis-à-vis more established immigrants, the second generation, and natives.

Likewise, our main results might pick up a broader association between changing perceptions and subjective well-being than changing perceptions of societal conditions alone. In particular, one might think about changes in one's perceptions of personal conditions. We test this possibility by expanding our main models to include two control variables related to the respondents' perceptions of personal conditions: job satisfaction (available in ESS rounds 5 and 6) and satisfaction with one's living standard (available in ESS round 3). The results, reported in Appendices $\mathrm{G}$ and $\mathrm{H}$, show that job satisfaction and satisfaction with one's living standard are not major drivers of the mediating role of the societal perceptions index. ${ }^{12}$ Nevertheless, with the data available, we cannot completely rule out that our index picks up faltering perceptions of other personal conditions.

\footnotetext{
12 Auxiliary analyses showed that optimism, job satisfaction, and satisfaction with one's living standard did not negatively mediate the relationship between the migrant's subjective well-being and length of stay.
} 
Our results are also robust to the alternative specification of variables. Our results hold when assessing subjective well-being using the global happiness measure instead of the life satisfaction measure (Online Appendix I). The results also hold for each of the index components independently, although the magnitudes of the mediating roles vary between the index components; the strong decline in economic satisfaction is most negatively related to subjective well-being assimilation while the relatively small decline in social trust has the least negative relationship with subjective well-being assimilation (Online Appendix J). Moreover, the non-significant interaction terms between length of stay and societal perceptions presented in Online Appendix $\mathrm{K}$ indicate that subjective well-being development is not further impaired by the declining returns (i.e., declining importance) of societal perceptions for subjective well-being.

One potential validity threat that cannot be addressed empirically in our study is cohort effects. ${ }^{13}$ This concern is alleviated by the inclusion of a rich set of control variables in our models that are likely to capture the main drivers of cohort differences in subjective wellbeing and perceptions of host society conditions. Particularly important control variables in this regard are the migrant's age, country of origin, and migration flow dummies. Another potential threat that cannot be addressed empirically is that of re-migration patterns. We expect the bias of re-migration to be small because re-migration resulting from having successfully achieved one's migration goals is to some extent counterbalanced by re-migration resulting from a disappointing migration experience (De Haas et al. 2015).

\section{Discussion and Conclusions}

The subjective well-being of immigrants in developed European countries generally does not improve with their length of stay or across generations, despite objectively improving living conditions and contrasting their own expectations and the rationale of "straightline" assimilation theory. The main finding of this paper is that faltering perceptions of host country conditions are associated with less positive subjective well-being trajectories among a wide variety of first-generation immigrants in developed European countries. This negative association is particularly strong for immigrants whose societal conditions strongly improved by migration and immigrants who arrived after childhood. The process of faltering societal perceptions continues to be negatively related to subjective well-being assimilation across generations. Finally, we find that compared with natives, the more positive societal perceptions of first-generation immigrants are associated with a subjective well-being advantage. Paradoxically, therefore, the non-assimilation of immigrants in terms of subjective well-being is associated with their assimilation to the less positive societal perceptions of natives.

Our findings provide useful input for policy initiatives that seek to improve the subjective well-being of immigrants and/or reduce the subjective well-being inequality between

\footnotetext{
13 While some variation between length of stay and migrant cohorts results from our pooling of survey rounds, this proved insufficient to disentangle the effects of length of stay from possible cohort effects, even when additionally considering rounds $1-4$. A major reason is that rounds $1-4$ cannot be included simultaneously, as the categorical length-of-stay variable does not allow for classifying migrants from these rounds into a consistent set of cohorts. When using a subset of survey rounds (e.g., rounds 1 and 5-8 or only rounds 5-8), multicollinearity issues arise between the cohort fixed effects and the length of stay variable (variance inflation factors $>10$ ).
} 
first-generation immigrants and natives. In particular, our findings suggest that a potential path towards more successful subjective well-being assimilation among immigrants would involve delaying or decelerating the process of immigrants' shifting frames of reference and faltering perceptions of host societies. This intervention could reduce immigrant frustrations about their perceived lack of progress in realizing their aspirations. Greater subjective well-being assimilation could also be instrumental in creating other benefits, such as better immigrant integration (Richardson 1967; De Neve et al. 2013). Therefore, an important question for future research and policymakers is how to delay or decelerate the changing frame of reference to benefit both immigrants and the host society. Possible opportunities include managing expectations (before and upon arrival as well as during the post-migration period) and encouraging migrants to adopt a dual frame of reference rather than abandoning all ties to the home country.

Building on Piore (1979), we suggest that an important reason for migrants' faltering perceptions of the host society is the development of growing aspirations that follow from their habituation to better conditions in their host country and fewer (more) comparisons to the inferior (better) conditions of the people in their home (host) country. A limitation of this research is that in the absence of data on migrants' reference points and aspirations (Gelatt 2013), we could not verify this rationale and therefore call for more research and better data sources that capture changes in immigrants' evaluation standards and frames of reference to examine this potentially pertinent process of shifting reference points and aspirations.

While this paper highlighted one specific mechanism that is negatively related to subjective well-being assimilation, there may be other mechanisms that impair migrants' subjective well-being assimilation. For example, Piore (1979) also argued that non-pecuniary factors became more salient once (labour) migrants were settled, including social exclusion, social networks, housing conditions, cultural/identity issues, and social status in the host country. To the extent that this involves a shift towards less positive aspects of life in the host society, this may be an additional explanation for why migrants' happiness growth will lag behind their objective gains. Future research could explore such additional mechanisms to develop a more all-encompassing explanation for migrants' stagnant level of subjective well-being.

We also call for more research and better data sources that can address additional limitations of our study. First, the role of subjective dimensions other than immigrants' perceptions of the institutional, economic, and social environment merit further attention. For instance, perceptions of other macro conditions (e.g., perceptions of the host society's cultural and natural environment) and personal conditions [e.g., perceptions of income; see Obućina (2013)] may also affect subjective well-being assimilation. Second, longitudinal or experimental studies can establish the direction of causality between immigrants' subjective well-being assimilation and their perceptions of their situations and circumvent some endogeneity issues that may be present in our cross-sectional study, including potential biases from re-migration patterns and cohort effects. Third, our immigrant sample may not be completely representative of the immigrant population in the considered destination countries because the employed dataset is not specifically oriented towards migrants. These limitations are typical in the international migration literature due to the lack of data collections that follow immigrants over time or that are representative of immigrant populations (Willekens et al. 2016). Although progress is being made (e.g., the migrant sample of the German Socio-Economic Panel), the time spans of the available longitudinal datasets are currently too short for meaningful analyses of the within-person process of subjective well-being assimilation. In addition, future research can test the role of declining societal 
perceptions in the subjective well-being assimilation of immigrants in non-European host countries. Fourth, the extent to which the mediating role of faltering perceptions is conditional on various other migrant characteristics that could not be explored with our data merits further attention. One can, for example, think here of the role of acculturation and reasons for migration.

Open Access This article is distributed under the terms of the Creative Commons Attribution 4.0 International License (http://creativecommons.org/licenses/by/4.0/), which permits unrestricted use, distribution, and reproduction in any medium, provided you give appropriate credit to the original author(s) and the source, provide a link to the Creative Commons license, and indicate if changes were made.

\section{References}

Akay, A., Bargain, O., \& Zimmermann, K. F. (2017). Home sweet home? Macroeconomic conditions in home countries and the well-being of migrants. Journal of Human Resources, 52(2), 351-373.

Alba, R., \& Nee, V. (1997). Rethinking assimilation theory for a new era of immigration. International Migration Review, 31(4), 826-874.

Arampatzi, E., Burger, M. J., Ianchovichina, E., Röhricht, T., \& Veenhoven, R. (2018). Unhappy development: Dissatisfaction with life in the wake of the Arab spring. Review of Income and Wealth, 64, S80-S113.

Berry, J. W., Phinney, J. S., Sam, D. L., \& Vedder, P. (2006). Immigrant youth: Acculturation, identity, and adaptation. Applied Psychology, 55(3), 303-332.

Böhme, M. H. (2015). Migration and educational aspirations: Another channel of brain gain? IZA Journal of Migration, 4(1), 1-24.

Calvo, R., \& Cheung, F. (2018). Does money buy immigrant happiness? Journal of Happiness Studies, 19(6), 1657-1672.

Cameron, A. C., Gelbach, J. B., \& Miller, D. L. (2008). Bootstrap-based improvements for inference with clustered errors. The Review of Economics and Statistics, 90(3), 414-427.

Chiswick, B. R., Lee, Y. L., \& Miller, P. W. (2005). Immigrant earnings: A longitudinal analysis. Review of Income and Wealth, 51(4), 485-503.

Clark, A. E., Frijters, P., \& Shields, M. A. (2008). Relative income, happiness, and utility: An explanation for the Easterlin paradox and other puzzles. Journal of Economic Literature, 46(1), 95-144.

Czaika, M., \& Vothknecht, M. (2014). Migration and aspirations: Are migrants trapped on a hedonic treadmill? IZA Journal of Migration, 3(1), 1-21.

De Haas, H., Fokkema, T., \& Fihri, M. F. (2015). Return migration as failure or success? Journal of International Migration and Integration, 16(2), 415-429.

De Neve, J.-E., Diener, E., Tay, L., \& Xuereb, C. (2013). The objective benefits of subjective well-being. In J. Helliwell, R. Layard, \& J. Sachs (Eds.), World happiness report 2013 (pp. 54-74). New York, NY: UN Sustainable Development Solutions Network.

De Vroome, T., \& Hooghe, M. (2014). Life satisfaction among ethnic minorities in the Netherlands: Immigration experience or adverse living conditions? Journal of Happiness Studies, 15(6), 1389-1406.

Depalo, D., Faini, R., \& Venturini, A. (2006). The social assimilation of immigrants. Center for Economic and Policy Research (CEPR) discussion paper no. 5992. Washington, DC: CEPR.

Diener, E., Lucas, R. E., \& Scollon, C. N. (2006). Beyond the hedonic treadmill: Revising the adaptation theory of well-being. American Psychologist, 61(4), 305-314.

Dinesen, P. T., \& Hooghe, M. (2010). When in Rome, do as the Romans do: The acculturation of generalized trust among immigrants in Western Europe. International Migration Review, 44(3), 697-727.

Easterlin, R. A. (2001). Income and happiness: Towards a unified theory. The Economic Journal, 111(473), $465-484$.

Ender, P. E. (2012). ml_mediation: Mediation for multilevel data. UCLA Academic Technology Services Statistical Consulting Group. https://stats.idre.ucla.edu/stata/ado/analysis/.

Farley, R., \& Alba, R. (2002). The new second generation in the United States. International Migration Review, 36(3), 669-701.

Ferrer-i-Carbonell, A., \& Frijters, P. (2004). How important is methodology for the estimates of the determinants of happiness? The Economic Journal, 114(497), 641-659.

Festinger, L. (1954). A theory of social comparison processes. Human Relations, 7(2), 117-140. 
Franzini, L., \& Fernandez-Esquer, M. E. (2006). The association of subjective social status and health in low-income Mexican-origin individuals in Texas. Social Science and Medicine, 63(3), 788-804.

Gelatt, J. (2013). Looking down or looking up: Status and subjective well-being among Asian and Latino Immigrants in the United States. International Migration Review, 47(1), 39-75.

Gokdemir, O., \& Dumludag, D. (2012). Life satisfaction among Turkish and Moroccan immigrants in the Netherlands: The role of absolute and relative income. Social Indicators Research, 106(3), 407-417.

Graham, C., \& Nikolova, M. (2015). Bentham or Aristotle in the development process? An empirical investigation of capabilities and subjective well-being. World Development, 68, 163-179.

Graham, C., \& Pettinato, S. (2001). Happiness, markets, and democracy: Latin America in comparative perspective. Journal of Happiness Studies, 2(3), 237-268.

Hayes, A. F. (2013). Introduction to mediation, moderation, and conditional process analysis: A regression-based approach. New York, NY: Guilford Press.

Helson, H. (1964). Adaptation-level theory: An experimental and systematic approach to behaviour. New York: Harper \& Row.

Hendriks, M. (2015). The happiness of international migrants: A review of research findings. Migration Studies, 3(3), 343-369.

Hendriks, M., Burger, M., Ray, J., \& Esipova, N. (2018). Do international migrants increase their happiness and that of their families by migrating? In J. Helliwell, R. Layard, \& J. Sachs (Eds.), World happiness report 2018 (pp. 44-66). New York: UN Sustainable Development Solutions Network.

Hirschman, A. O., \& Rothschild, M. (1973). The changing tolerance for income inequality in the course of economic development: With a mathematical appendix. The Quarterly Journal of Economics, $87(4), 544-566$.

Jahedi, S., \& Méndez, F. (2014). On the advantages and disadvantages of subjective measures. Journal of Economic Behavior \& Organization, 98, 97-114.

Johnson, K. J., \& Fredrickson, B. L. (2005). "We all look the same to me" Positive emotions eliminate the own-race bias in face recognition. Psychological Science, 16(11), 875-881.

Luhmann, M., Hofmann, W., Eid, M., \& Lucas, R. E. (2012). Subjective well-being and adaptation to life events: A meta-analysis. Journal of Personality and Social Psychology, 102(3), 592-615.

Manning, A., \& Roy, S. (2010). Culture clash or culture club? National identity in Britain. The Economic Journal, 120(542), F31-F51.

Maxwell, R. (2010). Evaluating migrant integration: Political attitudes across generations in Europe. International Migration Review, 44(1), 25-52.

Menjívar, C., \& Bejarano, C. (2004). Latino immigrants' perceptions of crime and police authorities in the United States: A case study from the Phoenix metropolitan area. Ethnic and Racial Studies, 27(1), 120-148.

Michalos, A. C. (1985). Multiple discrepancies theory (MDT). Social Indicators Research, 16(4), 347-413.

Michelson, M. R. (2003). The corrosive effect of acculturation: How Mexican Americans lose political trust. Social Science Quarterly, 84(4), 918-933.

Obućina, O. (2013). The patterns of satisfaction among immigrants in Germany. Social Indicators Research, 113(3), 1105-1127.

Okulicz-Kozaryn, A. (2013). City life: Rankings (livability) versus perceptions (satisfaction). Social Indicators Research, 110(2), 433-451.

Piore, M. (1979). Birds of passage: Migrant labor and industrial societies. Cambridge: Cambridge University Press.

Portes, A., \& Zhou, M. (1993). The new second generation: Segmented assimilation and its variants. The Annals of the American Academy of Political and Social Science, 530(1), 74-96.

Reese, L. (2001). Morality and identity in Mexican immigrant parents' visions of the future. Journal of Ethnic and Migration Studies, 27(3), 455-472.

Richardson, A. (1967). A theory and a method for the psychological study of assimilation. International Migration Review, 2(1), 3-30.

Röder, A., \& Mühlau, P. (2012). Low expectations or different evaluations: What explains immigrants' high levels of trust in host-country institutions? Journal of Ethnic and Migration Studies, 38(5), 777-792.

Rumbaut, R. G. (1997). Assimilation and its discontents: Between rhetoric and reality. International Migration Review, 31(4), 923-960.

Rumbaut, R. G. (2004). Ages, life stages, and generational cohorts: Decomposing the immigrant first and second generations in the United States. International Migration Review, 38(3), 1160-1205.

Safi, M. (2010). Immigrants' life satisfaction in Europe: Between assimilation and discrimination. European Sociological Review, 26(2), 159-176. 
Senik, C. (2014). The French unhappiness puzzle: The cultural dimension of happiness. Journal of Economic Behavior \& Organization, 106, 379-401.

Sjaastad, L. A. (1962). The costs and returns of human migration. The Journal of Political Economy, 70(5), 80-93.

Stark, O., \& Taylor, J. E. (1991). Migration incentives, migration types: The role of relative deprivation. The Economic Journal, 101(408), 1163-1178.

Stillman, S., Gibson, J., McKenzie, J., \& Rohorua, J. (2015). Miserable migrants? Natural experiment evidence on international migration and objective and subjective well-being. World Development, 65, 79-93.

Suarez-Orozco, M. M. (1987). "Becoming somebody": Central American immigrants in US inner-city schools. Anthropology \& Education Quarterly, 18(4), 287-299.

Veenhoven, R. (2012). Happiness: Also known as "life satisfaction" and "subjective well-being". In K. Land, A. Michalos, \& M. Sirgy (Eds.), Handbook of social indicators and quality of life research (pp. 63-77). Dordrecht: Springer.

Vertovec, S. (2009). Transnationalism. New York: Routledge.

Vohra, N., \& Adair, J. (2000). Life satisfaction of Indian immigrants in Canada. Psychology and Developing Societies, 12(2), 109-138.

Willekens, F., Massey, D., Raymer, J., \& Beauchemin, C. (2016). International migration under the microscope. Science, 352(6288), 897-899.

Zuccotti, C. V., Ganzeboom, H. B., \& Guveli, A. (2017). Has migration been beneficial for migrants and their children? International Migration Review, 51(1), 97-126.

Publisher's Note Springer Nature remains neutral with regard to jurisdictional claims in published maps and institutional affiliations. 